\title{
Economic Theory and Forecasting
}

\author{
Occasionally this Review publishes articles of a more technical nature. \\ These articles result from basic research efforts of staff economists.
}

Introtanthe

T HE ECONOMIC FORECASTS for 1967 have been duly recorded and only await the passage of time to see how accurate they were. This article does not attempt to add an additional forecast to those already made. Rather, it specifies some of the common underlying assumptions or theories which major groups of forecasters accept and which they implicitly or explicitly take into account in constructing a forecast.

It is hoped that this review of forecasting assumptions will help clarify some of the differences which separate those who forecast a substantial decline in the growth of gross national product (GNP) in 1967, with a resulting increase in unemployment, from those who project a high rate of growth in GNP and a continued tight labor market.

There is widespread interest in economic forecast. ing. It is of concern to the private citizen because of the information it may provide regarding his future income and employment. It is of interest to business firms which desire to plan their investment and production programs appropriately. It is of interest to the Government because its policy actions can affect the level of economic activity. Policymakers have some idea of a socially desirable level of economic activity. An accurate forecast tells what the actual level of economic activity is most likely to be. When actual and desired levels differ, appropriate application of monetary, fiscal, or other public policy may serve to move the actual closer to the desired value.

\section{Dinpural Forecasts}

Methods of economic forecasting may be divided into two major classes. One class uses primarily an empirical approach, while the other class combines economic theory with empirical evidence. The bestknown empirical approach to forecasting is the "leading indicators" technique. This was originally developed by the National Bureau of Economic Research (NBER) during the 1920's, and since 1961 data for applying this technique have been published monthly by the Department of Commerce in Btrsiness Cycle Developments. This technique consists of examining a wide range of economic data from previous business cycles to discover those time series which typically show peaks and troughs before peaks and troughs are observed in general business conditions.

The leading indicators approach is widely reported and discussed in the financial press. In the December 1966 issue of Business Cycle Developments (which presented the best information then available, when most forecasts of 1967 were being completed), the leading indicators were giving conflicting evidence about the future. A sampling of leading indicators published in the December issue is presented in the accompanying table. Some indicators showed continued expansion, others had turned down, and many were indeterminate. For example, in the last half of 1966 new orders received by durable goods industries and plant and equipment contracts and orders tended to increase at about the same rate as during the whole of the 1961-66 expansion period. By comparison, private nonfarm housing starts and stock market prices, two other leading indicators, showed well-publicized decreases. (Since December the stock market has shown renewed strength.) Also, many of the "coincident indicators," those which generally move simultaneously with peaks and troughs in business cycles, registered advances. Given this conflicting evidence plus uncertainties regarding Government spending for Vietnam, it is not surprising that there was a considerable degree of uncertainty in the projections of many forecasters.

To evaluate the mass of largely conflicting evidence available to forecasters, some judgment about what are important and what are secondary causes of changes in the economy are needed. It is in this context that the second class of forecasting tools (the

\footnotetext{
1Some attempts have been made to apply an objective statis. tical test to see if a mixture of leading and coincident indicators point to contintued expansion or contraction. For example, see Leonall C. Andersen, "A Method of Using Diffusion Indexes to Indicate the Direction of National Economic Activity," 1966 Proceedings of the Business and Economic Statistics Section, American Statistical Association (Washington, D. C. ), pp. 424-434.
} 


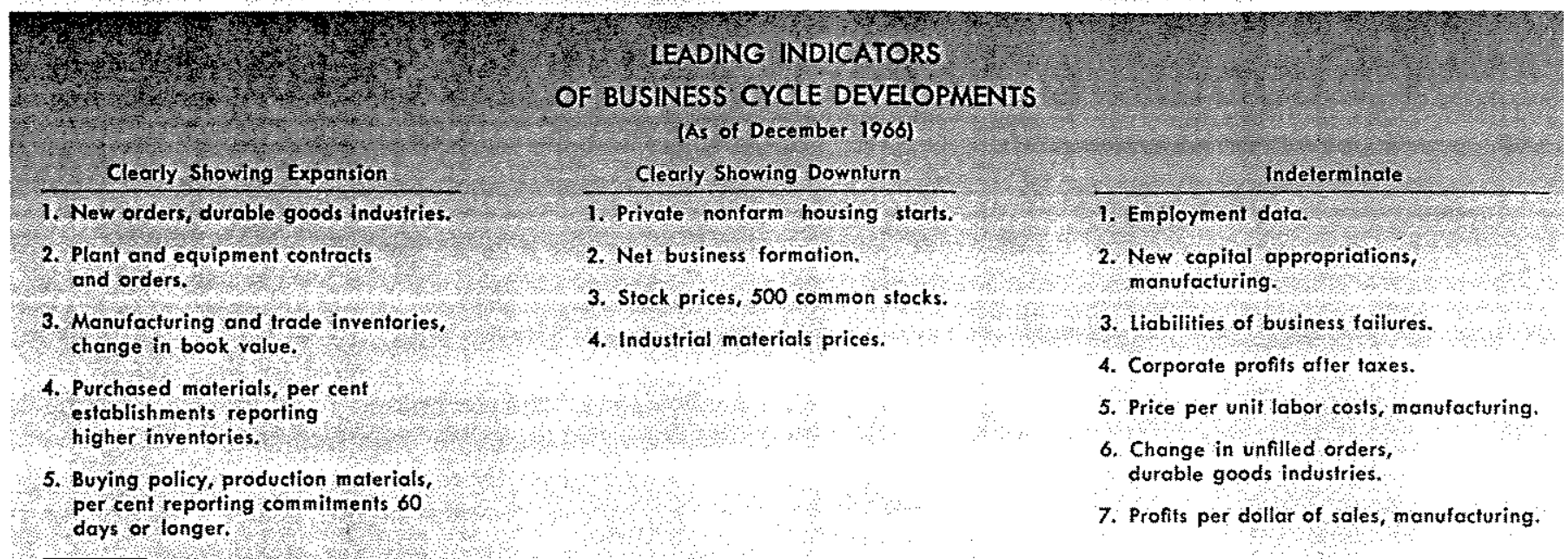

Note: This is a representative sampling from a larger list of leading indicators.

Sowter US. Department of Commerce, Burean of the Census, Business Cycle Developments, December 1966.

मे

combination of economic theory and empirical evidence) plays an important role. ${ }^{2}$

\section{Economic Theory and Forecasting}

A theory which attempts to explain the determinants of national income should also provide some insights into the future level of national income. This is especially true if changes in the determinants of income as postulated by the theory generally occur prior to actual changes in income. For example, if one knows for some previous time period $(t-1)$ the value of the determinants of income, one is in a strong position to predict the value of income in the subsequent time period $(t)$. But even if there is no time lag between the theoretical determinants of income and their effect on income, theory may, nevertheless, help in forecasting. The determinants of income may be easier to predict, or certainly more subject to direct influence by the monetary or fiscal authorities, than the aggregate level of income.

Since economics is far from an exact science, more than one theory about the operation of the economy may be consistent with the available statistical evidence. Theories of national income determination representing the two major schools of thought which presently influence professional economic thinking in the United States are considered here in a highly simplified form. One is the quantity theory of money

\footnotetext{
2 Economic theory plays a larger role than factitating forecasting-it also helps explain the underlying structural relations in the economy. The application of theory, mathematical reasoning, and statistical technique to establish the actual value of these structural relations is called econometrics. Forecasting is only one application of the results of this type of research.
}

and the other is the income-expenditure theory. The quantity theory of money dominated economic think. ing until the middle of the 1930 's when John Maynard Lord Keynes income-expenditure theory came into prominence. The quantity theory has recently reemerged under the intellectual leadership of such economists as Professor Milton Friedman of the University of Chicago and Professor Karl Brunner of Ohio State University. However, the income-expenditure theory is still dominant in professional economic thinking.

Because of the important role these two theories play in influencing the thinking of present-day economists and economic policymakers, it is useful to (1) review brielly the rationale of each theory; (2) consider the experience of each theory in explaining developments in national income during the present business cycle (1960 to 1966); (3) indicate how each theory might forecast national income for 1967 , and (4) consider the possibility of a mix of these two theories.

\section{The Theoretical Frameworks ${ }^{3}$}

The proponents of the quantity theory of money consider that the desire to hold a given stock of money is predictably related to income, wealth, interest rates, and possibly some other strategic economic variables.

3 The following is an extremely simple statement of what are in fact highly complex explanations of the determination of national income. The interested reader is referred to any standard text on national income analysis for a more complete discussion, e.g., Gardner Ackley, Macroeconomic Theory (New York: The Macmillan Company, 1961), and Joseph P. McKenna, Aggregate Economic Analysis (New York: Henry Holt and Company, Inc., 1955). 
Based on the value of these variables, all spending units are considered to desire a certain amount of money to hold. This theory also postulates that discretionary actions by the Federal Reserve can alter the actual stock of money relative to the desired stock, thereby setting into action a course of events which leads to a change in income and interest rates. When the actual stock of money differs from the desired stock, a response is induced on the part of the public to re-establish the desired relation. This attempt to shift between money and other financial assets or commodities affects interest rates and aggregate demand and through these the level of prices and real output.

The income-expenditure theory divides expenditures into two groups-those which are induced or are dependent on current income and those which are autonomous or are independent of current income. Most consumption spending is considered to depend upon income and is therefore the major induced expenditure. Autonomous expenditures (as defined in this article) are investments of business firms, government expenditures, the net export surplus, and some minor items. ${ }^{4}$ Although autonomous spending is independent of current income, it is, of course, dependent on something. Government spending depends upon the policy decisions of the President, Congress, and their advisers; business investment depends upon such factors as expectations of future sales, changes in technology, and interest rates; exports depend upon income and prices in the rest of the world and the exchange rate. By definition, the sum of induced and autonomous expenditures is equal to the total value of all goods and services produced in the economy, i.e., GNP. Thus, autonomous spending is one component of GNP, but the level of GNP does not directly determine the amount of attonomous spending.

The proponents of the income-expenditure theory postulate that consumption expenditures are very closely tied to the level of income and thus cannot generally act as a substantial initial cause of shortterm changes in income. Consequently, changes in autonomous expenditures are considered the major

4There is considerable controversy among economists about which components of income are induced and which are autonomous. See Appendix, page 14, for some discussion of this and other issues.

5 The income-expenditure theory considers certain exceptions in the dependence of consumption on income. (1) A sharp change in the public's expectations about future prices or availability, such as took place in the early months of the Korean War, can temporarily increase the consumption-income relation cause of changes in income. This is not only because autonomous spending is a component of income, but also (and more importantly) because autonomous spending actually induces changes in consumption. The Government, through its control of expenditures, affects the level of autonomous spending, thereby influencing consumption and GNP.

The formal structure of each theoretical model is presented in the following highly simplified equations:

Quantity Theory of Money

1. $\Delta \mathrm{Y}_{\mathrm{t}}=\mathrm{e}+\mathrm{v}(\Delta \mathrm{M})_{\mathrm{t}-\mathrm{n}}$

Income-Expenditure Theory

2. $\Delta Y_{t}=a+b(\Delta A)_{t-m}$

$$
\begin{aligned}
\mathrm{Y} & =\mathrm{GNP} \\
\mathrm{M}= & \text { Money } \\
\mathrm{A}= & \text { Autonomous spending } \\
\mathrm{t}= & \text { time unit which is one-quarter of a year } \\
\mathrm{t}-\mathrm{n}, \mathrm{t}-\mathrm{m}= & \text { different possible time lags between } \\
& (\mathrm{M}) \text { and }(\mathrm{Y}) \text { and between }(\mathrm{A}) \\
& \text { and }(\mathrm{Y}) \\
\Delta= & \text { change between quarters }
\end{aligned}
$$

The symbols, e, v, a, b, represent specific statistically determined values relating (M) to (Y) and (A) to (X). The quantity theory of money (equation 1 ) says that short-term movements in GNP $(\Delta Y)$ are largely determined by changes in the stock of money $(\Delta \mathrm{M})$. The income-expenditure theory (equation 2) says that changes in autonomous spending $(\Delta A)$ determine short-term movements in GNP $(\Delta \mathrm{Y}){ }^{7}$

\section{(Continued from col. 1 )}

because of scare buying. (2) There may be a change in tastes of the public or temporary saturation of the market which could decrease consumption of some product although income is unchanged. The first factor has been sufficiently unpredictable that it would be unprofitable to incorporate it into a general theory explaining consumption. The second factor may be of major importance in analyzing a particular comnodity market (like autos), but it has not been a major factor in causing changes in overall consumption.

6everal definitions of money are used in economic literature. The standard defnition of money, which is used here, is currency held outside of commercial banks plus demand deposits adjusted (referred to as M1). Some economists consider this definition too narrow because it excludes other imporfant sources of household and business liquidity. A broader definition which is sometimes used is M1 plus time deposits in commercial banks (referred to as M2).

${ }^{7}$ Those economists who consider that both theories jointly explain how GNP is determined might say that monetary variables (through the interest rate) will affect autonomous spending, while autonomous variables (through demand for bank credit, etc.) will affect the money supply. According to this view, independent changes in either money or autonomous variables, or both, determine the level of GNP. 
The obvious policy difference between the two theories is that the first emphasizes the role of money and central bank monetary policy in determining GNP, while the second emphasizes the role of autonomous expenditures and Government fiscal policy in determining GNP. In the event that movements in money and autonomous expenditures are in different directions, very different conclusions as to the future course of GNP would be forecast by proponents of each of the theories.

A case in point is the recent economic experience in this country. From the second to the fourth quarter of 1966 the economy experienced a period of tight money but a continuing stimulative fiscal policy. The proponents of the quantity theory might reasonably forecast for 1967 a marked decline in the growth of GNP and real output. On the other hand, proponents of the income-expenditure theory would most likely expect continued growth in GNP at a relatively rapid rate.

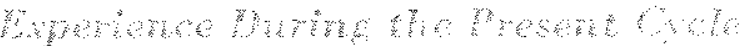

One way to examine these theories is to compare movements in GNP with each of the theoretically postulated determinants of GNP, i.e., money and autonomous spending, to see how closely each has moved with GNP. Because there are strong upward trends in money, GNP, consumption, and autonomous spending, turning points in the data may not easily be observed. To remove most of the trend and therefore to concentrate on the cyclical elements in income, its components, and money, quarterly changes in each series are used. $^{8}$

In Chart 1 quarterly changes in money and GNP are plotted from 1958 (4th quarter) to 1966 (4th quarter). In Chart 2 quarterly changes in autonomous spending

BThe generally accepted convention in computing changes for any time period $(t)$ is to consider the difference between $(t-1)$ and $(t)$. However, there is no necessary reason for this. The change at (t) could also be measured as the difference between ( $t)$ and $(t+1)$. The value of the change at $(t)$ used here is the average of these two measures of change. The practical advantage of this approach is that it reduces much of the random statistical "noise" (movement) which results from the use of first differences computations.
(A), consumption (C), and GNP (Y) are plotted for the same time period. The relationship between $(\Delta M)$ and $(\Delta Y)$ or $(\Delta A)$ and $(\Delta Y)$ can be estimated statistically to get a quantitative measure of the value of the relation and its statistical significance. Using the same data as plotted in Charts 1 and 2 , the following estimates were computed:

The Quantity Theory

$$
\text { 1a. } \begin{aligned}
\Delta \mathrm{Y}_{\mathrm{t}}=5.61+ & 3.94(\Delta \mathrm{M})_{\mathrm{t}-3} \quad \mathrm{r}^{2}=.553
\end{aligned}
$$

The Income-Expenditure Theory

$$
\text { 2a. } \Delta \mathrm{Y}_{\mathrm{t}}=4.94+1.08(\Delta \mathrm{A})_{\mathrm{t}-1} \quad \mathrm{r}^{2}=.400
$$

The quantity theory result indicates that in each quarter GNP ( $Y$ ) will increase $\$ 5.6$ billion (at annual rates) plus $\$ 3.9$ billion for every $\$ 1.0$ billion increase in the stock of money (M) three quarters previously. The number in brackets (.69) is a measure of the degree of error in this estimate. As it is only about one-sixth the value of the coefficient (3.94), one car be reasonably confident that the relationship is statistically significant. The coefficient of determination $\left(\mathrm{r}^{2}\right)$ indicates that 55 per cent of the variance in $(\Delta Y)_{2}$ could be explained by changes in $(\Delta M)_{1-3}{ }^{10}$

9The three-quarter lag in the quantity theory and the onequarter lag in the income-expenditure theory are based on best statistical fit.

10 Using the broader definition of money (M2), the relation between $(M)$ and $(Y)$ is even closer. Changes in $(\Delta M 2)_{t-3}$ explain 67 per cent of the variance in $(\Delta Y)$.

$$
\text { Chart } 1
$$

Changes in Nominal GNP and Money Supply

Quorterly Doto at Annual Rates, Seasonclify Adjusted

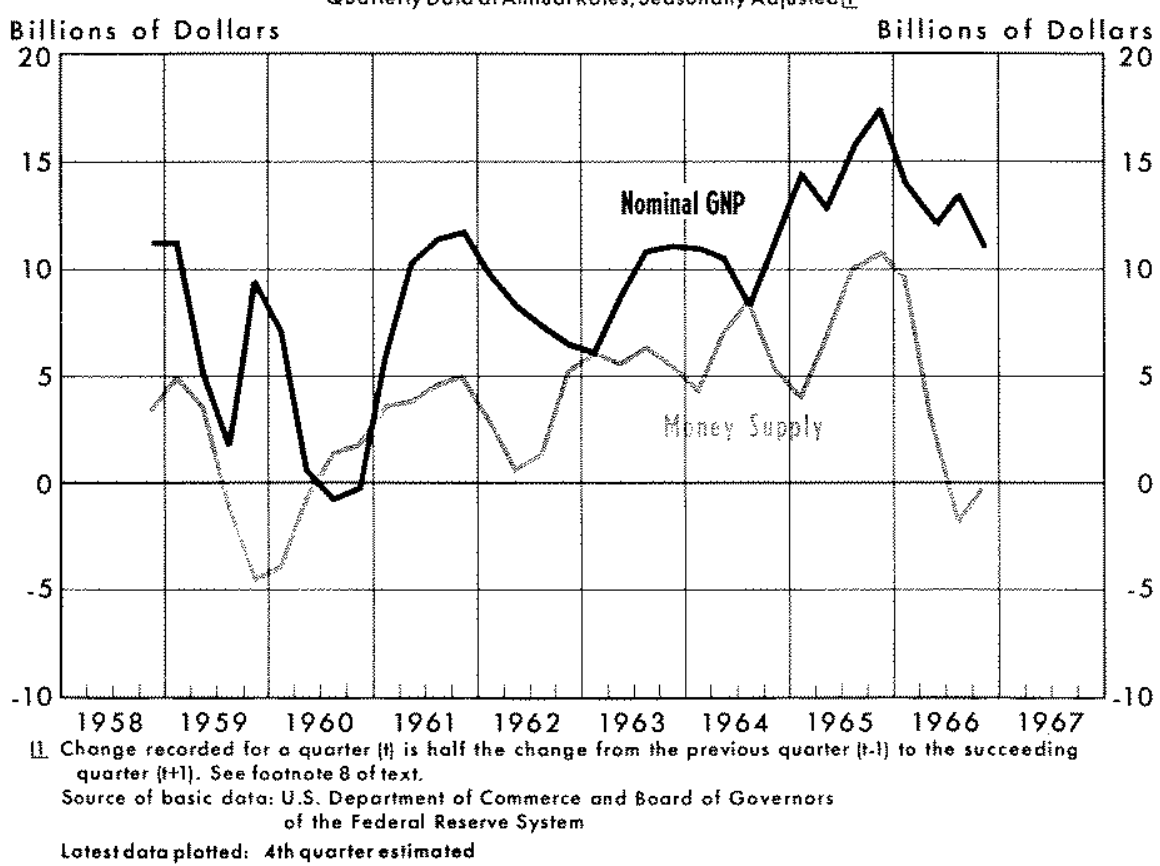


Chart 2

Changes in GNP, Consumption, and Autonomous Spending

Quarlerly Data at Annual Rates, Seosonaliy Adjustedu
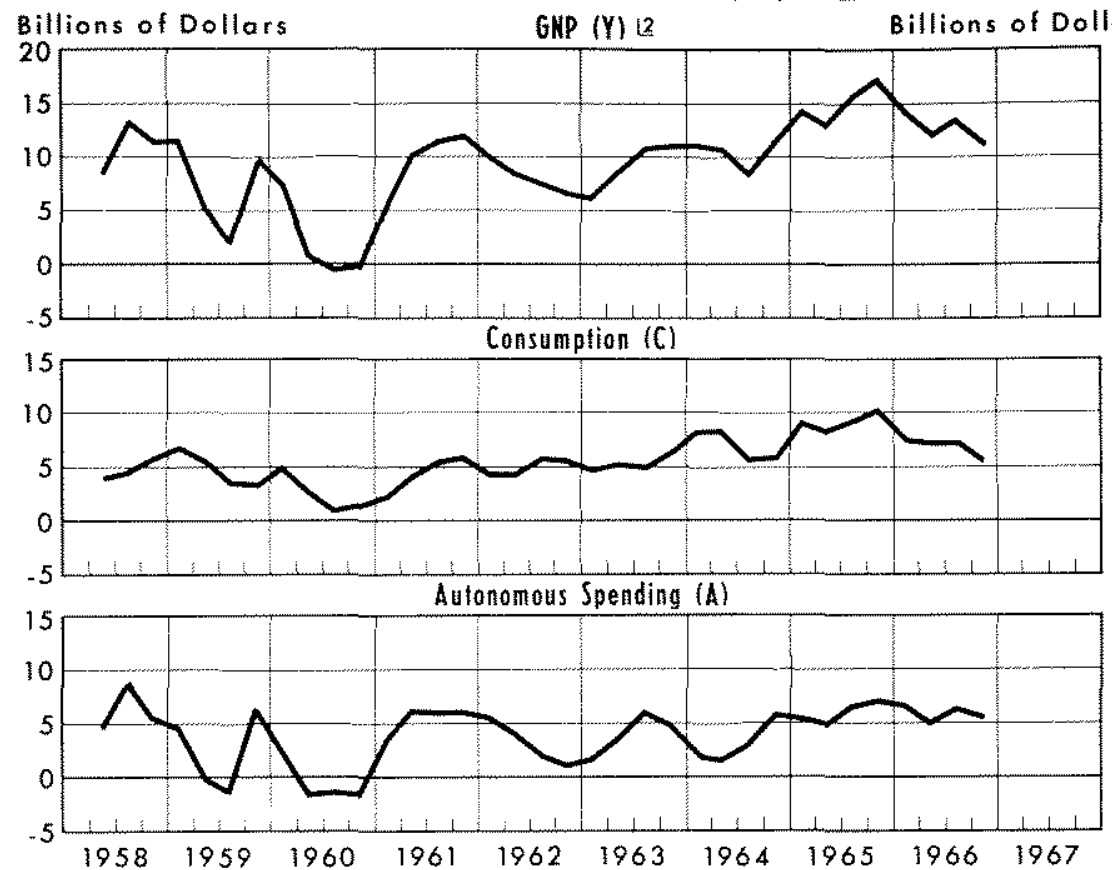

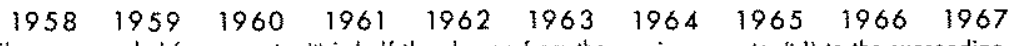

[1 Change recarded for a quarter it is halt the change from the previous quarter $[\mathrm{t}-1]$ to the succeeding quarter littil. See footrobe 8 of text

$2 \mathrm{Y}=\mathrm{C}+\mathrm{A}$

Source of basic data: U.S. Department of Commerce

Latest diato plotsed: th quarterestimated

The income-expenditure theory result indicates that in each quarter GNP increases $\$ 4.9$ billion plus $\$ 1.1$ billion for every $\$ 1.0$ billion increase in autonomous spending (A) in the previous quarter. This coefficient is also statistically significant and 40 per cent of the change in $(\Delta Y)_{t}$ can be explained by changes in $(\Delta A)_{t-1}$.

In Charts 1 and 2 tuming points can be observed in each series. ${ }^{11}$ In Chart 1 the upper turning points in the money time series generally occur in the same quarter as the upper turning points in the income series. On the other hand, the lower turning points in money lead the lower turning points in income by two to three quarters. One possible implication of this is that GNP responds promptly to a decline in a monetary variable but responds sluggishly to an increase. Even quite small movements in GNP appear to be associated with small movements in money. The moderate deceleration in money in the middle of 1962 is related to the moderate deceleration in GNP in late 1962 and early 1963. On the other hand, larger

11 The turning points or peaks and troughs in the first difference series are not the same as business cycle turning points as determitied by the National Bureau of Economic Research. NBER business cycle turning points are determined from a number of factors, but they are influenced heavily by the level of income. One would expect the NBER turning points to occur after tuming points described here because a deceleration in income generally occurs before a decline in income. movements in GNP are associated with large movements in money. For example, the sharp deceleration in money in late 1959 and early 1960 compared with a sharp deceleration in GNP in mid- and late 1960.

Changes in autonomous expenditures (A) are related to changes in GNP (Y) and consumption (C) in Chart 2. ${ }^{12}$ In this case there is also a similarity between the movements in the time series, with (A) slightly leading (C). The major deceleration in autonomous spending from the second quarter of 1960 to the fourth quarter of $1960 \mathrm{com}$ pares with the deceleration in consumption spending from the third quarter of 1960 to the first quarter of 1961. The acceleration in autonomotis spending beginning in the first quarter of 1961 compares with the acceleration in consumption and GNP from the second quarter of 1961. Complementary movements between these two series are observed for other time periods. There is, however, one case where a deceleration in autonomous spending (from the third quarter of 1962 to the first quarter of 1963) was not associated with any significant deceleration in the growth of consumption spending.

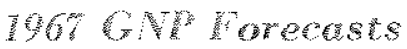

To forecast national income for 1967 on the basis of the two theoretical frameworks requires a projection of the course of money and autonomous spending during 1967. The best statistical fit observed between money and GNP over the last eight years was with changes in money three quarters before the changes in GNP. Thus, on the basis of currently available information the quantity theory would indicate that, given the decline in the stock of money through the fourth quarter of 1966 , it is highly probable there will be a substantial slowdown in the growth of GNP at least until the third quarter of 1967 . Given the stock

12 We camnot compare statistically the relationship between autonomous spending (A) and GNP (X) in the same time period because $(A)$ is a component of $(Y)$. Variations in automomous spending would lead to variations in income not because of the causal link postulated in the theory but because of a statistical artifact. To avoid this problem, (A) can either be related to the other component of income which, in this case, is consumption spending (C), or (A) can be related to (X) with a time lag. The second possibil ity is considered here and the first is considered in the Appendix. 
of money through 1966 , continuation of the average relationship between money and GNP which has existed over the past eight years would imply a growth in nominal GNP of about $\$ 22$ billion (at an annual rate) from the fourth quarter 1966 to the third quarter 1967. This is about one-half the rate of growth for the same period in 1966. To estimate GNP for all of 1967 requires a prediction of changes in the stock of money during the first quarter of 1967. Money declined about $\$ 1$ billion in the last half of 1966. It has shown little change thus far this year from the average of the fourth quarter of 1966. If this unchanged state continues during the rest of the first quarter of 1967, then GNP would increase about $\$ 28$ billion or 3.7 per cent from the fourth quarter of 1966 to the fourth quarter of 1967 , or from $\$ 759$ billion to $\$ 787$ billion. This is much smaller than the $\$ 55$ billion or 7.8 per cent increase from the fourth quarter of 1965 to the fourth quarter of 1966.

Given the way in which the quantity theory has been stated here, there is no way of knowing how the increase in GNP in 1967 will be distributed between price increases and real increases. However, there seems to be wide agreement that even with a decline in the growth of GNP the inflationary momentum developed in 1966 will carry over into 1967 in the form of cost-push, with average prices increasing about 2.5 per cent. The growth in real output consistent with this calculation would be between 1.0 and 1.5 per cent from the fourth quarter of 1966 to the fourth quarter of 1967, down substantially from the 4.1 per cent growth for the same period in 1966. This forecast of 1967 growth in real GNP is below the growth in capacity, which is generally estimated at about 4 per cent. This implies some increase in unemployment in 1967. Milton Friedman, a major exponent of the quantity theory approach, has predicted (Newsweek, October 17, 1966 and January 9, 1967) that the U.S, economy would suffer a recession in 1967 on the basis of the decline in the money supply in the last half of 1966.

Forecasting 1967 GNP on the basis of the incomeexpenditure theory requires a projection of autonomous spending through most of 1967 . This is because the best statistical relation between changes in autonomous spending $(\Delta A)$ and GNP $(\Delta Y)$ is with a onequarter time lag. To predict the course of GNP during 1967 with only a one-quarter forecasting horizon requires estimates of $(\Delta A)$ through the third quarter of 1967. Autonomous spending consists mainly of business investment and Government spending. This is why many forecasters emphasize the need to estimate these variables before any projection of GNP can be attempted. If these estimates are unreliable, the re- sulting forecast of GNP will also be poor. But this does not imply that the theory underlying the forecast is necessarily wrong.

According to the Department of Commerce-SEC Survey of Business Intentions released in December 1966, investment in 1967 will be 7 per cent above the 1966 level. The increase from the fourth quarter of 1966 to the fourth quarter of 1967 will be smaller (perhaps a 4 per cent increase). On the other hand, Government spending, especially because of the Vietnam War, is estimated in the budget to be about 13 per cent or $\$ 16$ billion higher in the fourth quarter of 1967 than in the fourth quarter of 1966. The export surplus should also be larger. On the assumption of no significant increase in tax rates, ${ }^{13}$ the sum of all of this autonomous spending should grow at a healthy, though somewhat reduced, rate in 1967 as compared with 1966. This would imply a fourth quarter to fourth quarter increase in GNP of $\$ 45$ to $\$ 50$ billion, about 6.5 per cent. Making the same assump tion about prices as in the discussion of the quantity theory, this forecast would imply growth in real output of approximately 4 per cent. This is the same as the rate of growth in capacity. Consequently, the labor market will continue to remain tight, with the unemployment rate at 4 per cent or below. Professor Lawrence Kline of the University of Pennsylvania, a leading exponent of the income-expenditure school, has constructed an econometric model of the U.S. economy. The output of this model as reported in the December 3, 1966 issue of Business Week is a $\$ 48$ billion or 6.3 per cent increase in nominal GNP from the fourth quarter of 1966 to the fourth quarter of 1967. A Michigan University econometric model, also based on the income-expenditure theory (the published results of which are only available on a calendar year basis), gives similar results.

These alternative forecasts can be presented graphically. In Chart 3 they are represented as projected movements in the level of real and nominal GNP. The preliminary value of nominal CNP for the fourth quarter of 1966 is $\$ 759$ billion. The quantity theory would forecast GNP to grow to the level of $\$ 787$ billion by the fourth quarter of 1967. The incomeexpenditure theory would forecast growth to a level of about $\$ 805$ billion. Similar projections are shown for real GNP in 1958 prices. In Chart 4 the alternative forecasts are presented as projections of per cent

\footnotetext{
${ }^{13}$ In the January 10, 1967 State of the Union Message the President proposed a 6 per cent surtax on personal and corporate income effective July I, 1967. Even if adopted as proposed, the effect on GNP estimates for 1967 as a whole would probably be small.
} 


\section{Chates}

Nominal and Real GNP

Quorterty Totals at Annual Rotes

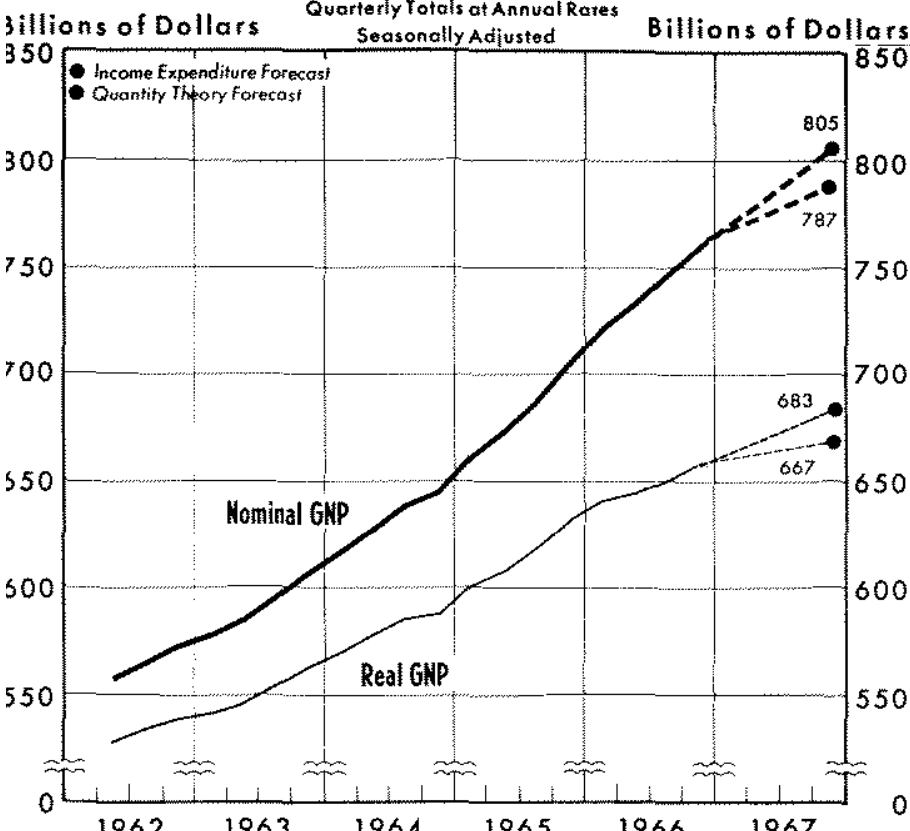

changes in real and nominal GNP. As these forecasts are on a fourth quarter-to-fourth quarter basis, the projection into 1967 must be viewed as an average value during the year rather than as a specific estimate of growth in the fourth quarter of 1967.

The year 1967 will provide an interesting testing ground for the predictability of the quantity theory as against the income-expenditure theory. These two views of the determination of GNP have been consistent with each other during the present business cycle. Each has predicted about the same movement in GNP. However, with the recent decline in the stock of money, the quantity theory predicts a substantial decline in the growth of GNP and the emergence of some unemployment. The income-expenditure theory, on the other hand, predicts only a moderate lessening in inflationary pressures, with real output growing at roughly the same rate as capacity. Depending upon the actual course of events in 1967, one theoretical view or the other will be given substantial empirical support.

\section{The Middle Ground}

The two theories discussed above represent extreme statements about the determinants of GNP. One says that GNP is determined in the short run only by financial factors (money). The other states that GNP is determined only by autonomous real factors. These strongly divergent views reflect a real division of opinion in the economics profession as to the fundamental forces which determine short-term move- ments in GNP.

It should be kept in mind, however, that there is also a trend towards synthesizing these two theoretical views. A large middle group of professional economic opinion holds that both financial and autonomous real factors play a role in jointly determining GNP. When changes in money $(\Delta M)$ and autonomous spending $(\Delta A)$ are simultaneously used in an equation to determine quarterly changes in GNP $(\Delta Y)$, the results are as follows:
3. $\Delta Y_{t}=4.00+$
$(\Delta \mathrm{M})_{\mathrm{t}-3}+$
$.670(\Delta \mathrm{A})_{\mathrm{t}-1}$
$(.241) \quad \mathrm{r}^{2}=.658$

According to equation 3 , quarterly changes in GNP $(\Delta Y)$, will equal $\$ 4.0$ billion (at an annual rate) plus $\$ 2.5$ billion for every $\$ 1.0$ billion increase in money three quarters previously plus $\$ 0.7$ billion for every increase of $\$ 1.0$ billion in autonomous spending one quarter previously. The values of the coefficient for $(\Delta M)$ and $(\Delta A)$ are both significant in a statistical sense and the equation explains 66 per cent of the variance in $(\Delta Y)$. It should be noted that equation 3 explains a greater per cent of the variance in GNP $(\Delta Y)$ than either the quantity theory or the incomeexpenditure theory separately. Proponents of the synthesis view might argue that this is because it reflects the real-world situation more accurately. ${ }^{14}$

\section{Changes in Nominal and Real GNP}

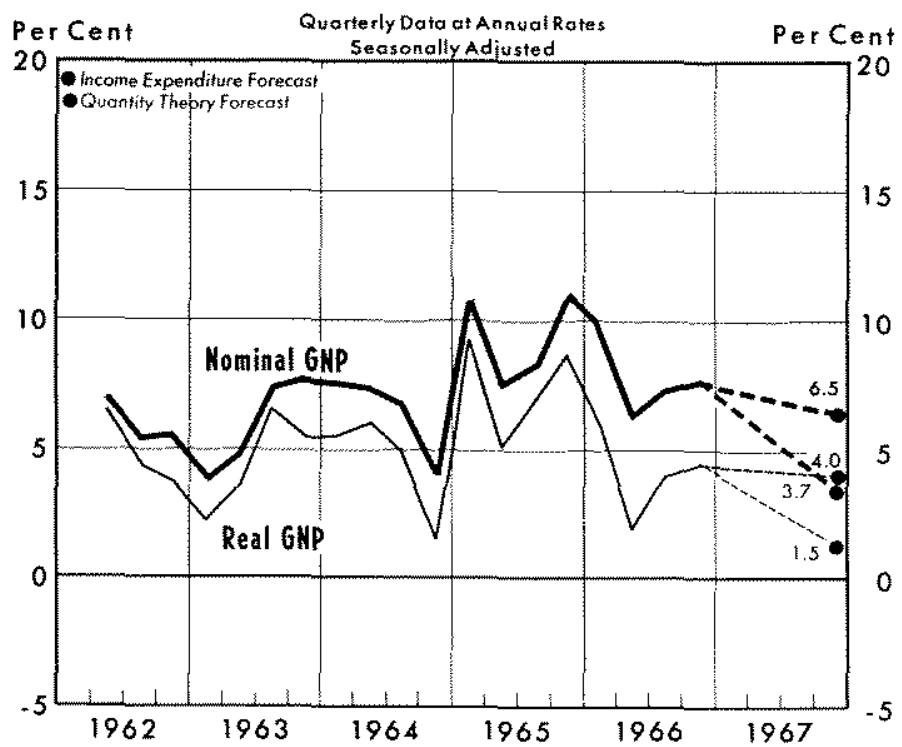

${ }^{14}$ An alternative explanation is that $(\Delta M)_{t-3}$ determines $(\triangle \mathrm{A})_{\mathrm{t}-\mathrm{t}}$ and $(\triangle Y)_{t}$. Therefore, including $(\triangle A)_{t-1}$ as one of the determinants of $(\Delta \mathrm{Y})_{\mathrm{t}}$ is an indirect way of counting $(\Delta \mathrm{M})_{\mathrm{t}-\mathrm{s}}$ twice. This possibility is supported by the results of another statistical test. The partial correlation coefficient between $(\Delta M)_{t-3}$ and $(\Delta Y)_{t}$ holding $(\Delta A)_{t-1}$ constant is 0.769 . The partial correlation coefficient between $(\triangle A)_{t-1}$ and $(\triangle Y)$, holding $(\triangle \mathrm{M})_{\mathrm{t}-3}$ constant is 0.486 . Thus, the independent contribution of $(\Delta \mathrm{A})_{\mathrm{t}-1}$ to $(\Delta \mathrm{Y})_{\mathrm{t}}$ is relatively small. 
This synthesis would not view either monetary or fiscal policy as the dominant tool of Government action to the exclusion of the other. Rather, it would consider that there is a possible mix of monetary and fiscal policies which can simultaneously achieve desired levels of income.

The most likely reason for the existence of the divergent theories described above is that one theoretical approach or the other may do a superior job of explaining short-term movements in GNP depending upon factors which are not explicitly considered in either theory. For example, during the 1930's business expectations of the future were so badly impaired by the depression experience that even large changes in financial variables like money, bank credit availability, and interest rates would not be sufficient to induce new investment and consumption. In this case, the income-expenditure theory would seem to provide a superior explanation of short-term movements in GNP. On the other hand, at other periods when business expectations of the future are buoyant, as the last five years, the major restriction on new investment and consumption is the availability of money and credit, which would make the quantity theory a superior explanation. At still other times, business expectations may be between these two extremes, in which case a mix or synthesis of the two theories may provide the best explanation of short-term movements of GNP.

Mromaet W. Kerat

\section{APPENDIX}

The method of testing the respective theories of income. determination used here is similar to one originally devised by Milton Friedman and David Meiselman in an article published in 1963 as "Research Study Two: The Relative Stability of Monetary Velocity and the Investment Multiplier in the United States, 1897-1958" in Stabilization Policies, one of a series of research studies prepared for the Commission on Money and Credit. The purpose of that study was to test empirically the stability of the fundamental behavioral assumptions underlying each theory. To do this, they selected definitions of GNP $(Y)$, autonomous spending (A), consumption (C), and money (M) which seemed to them most appropriate to that task. Since publication of that study there has been much controversy within the economies profession ${ }^{1}$ regarding the appropriateness of using a single-equation model to test competing theories and also regarding the appropriate definitions of major variables. The purpose of this article is not to test these theories but only to consider their use as forecasting tools. We have used the definitions of $(\mathrm{Y}),(\mathrm{A}),(\mathrm{C})$, and (M) which are most widely recognized by the general public although they differ in important respects from the definitions used by Friedman and Meiselman.

\footnotetext{
1 See American Economic Review, September 1965, "The Relative Stability of Monetary Velocity and the Investment Multiplier," by Albert Ando and Franco Modigliani; "Test of the Relative Importance of Autonomous Expenditures and Money," by Michael DePrano and Thomas Mayer; "Reply to Ando and Modigliani and to DePrano and Mayer," by Milton Friedman and David Meiselman. Also see Revtew of Economics and Statistics, November 1964, "Keynes and The Quantity Theory: a Comment on the Friedmar:-Meiselman CMC Paper" by Donald D. Hester, and "Reply to Donald Hester," by Friedman and Meiselman.
}

Each theory is presented as a single-equation model, while the true structure of the economy, and thus the structure of any model which attempts to explain the economy, is considerably more complicated. However, the use of a single-equation model of ench theory may be justified for several reasons. (1) At the theoretical level these singleequation models can be thought of as representing re duced forms of a more complex structural model of the economy. The intermediate links between the fundamental causal factors (money or autonomous spending) and GNP are netted out. (2) The causal differences between each theory as presented here are sufficiently large (one emphasizing financial factors and the other real factors) that as a first approximation a very crude single-equation model may distinguish between them. (3) As a practical matter, an economic model used just for forecasting future income can be simpler than a model designed to explain the structure and interrelationships of the economy.

The measure of aggregate economic activity used here as a forecasting target is GNP. The use of gross national product rather than net national product, national income, or disposable income can be criticized for a variety of theoretical and statistical reasons. The major justifeation for using GNP is that it is the most publicly recognized aggregate measure of economic activity. It is also the most widely forecast value of aggregate economic behavior, and results obtained here can be compared with other forecasts. If this article were designed to test the theoretical and empirical "correctness" of these two theories (which, it should be noted, is not the case), then some measure other than GNP might have been superior. 
There has been relatively little controversy among professional economists about the procedures for testing the significance of the quantity theory, with the possible exception of discussion of the appropriate definition of money (see footnotes 6 and 10 in the text). However, with respect to the income-expenditure theory, a major problem is the method of specifying what is autonomous spending and what is induced spending. It is difficult, if not impossible, to distinguish statistically which components of income are induced and which components are autonomous. Some elements in personal consumption, like durable goods, are only weakly related to current income. On the other hand, some part of business investment is induced by changes in current income. In this article all consumption is considered induced and all investment is considered autonomous.

A related problem is the treatment of imports and taxes in the analysis. Although neither of these items appears explicity, both are included implicitly and their inclusion complieates the distinction between autonomous and induced spending.

The value of GNP in the national income accounts does not include taxes directly. Imports, however, are netted against exports. That is, GNP is defined as

$$
\text { 1. } \begin{aligned}
\mathrm{Y}=\mathrm{C} & +\mathrm{Ig}+\mathrm{C}+(\mathrm{X}-\mathrm{Im}) \\
\mathrm{Y} & =\mathrm{GNP} \\
\mathrm{C} & =\text { Consumption } \\
\mathrm{Ig} & =\text { Gross business investment } \\
\mathrm{G} & =\text { Government spending } \\
\mathrm{X} & =\text { Exports } \\
\mathrm{Im} & =\text { Imports }
\end{aligned}
$$

It is necessary to define induced and antonomous spending in such a way that their sum will equal GNP (Y). Considering these problems, induced spending (I) and autonomous spending (A) have been defined as follows:

$$
\begin{aligned}
& \text { 2. } I=C \\
& \text { 3. } A=I g+G+(X-I m)^{2}
\end{aligned}
$$

This problem of adjusting the values of (I) and (A) to make them consistent with (Y) will arise no matter what definition of income is used. Because this adjusting process is rather arbitrary, reasonable men could disagree with the specific adjustments used. The rationale for the adjustments made here are given in the two following paragraphs.

Imports are already included in the recorded value of consumption, investment, and govemment spending. Thus, the major behavioral role of imports broken down according to its induced and autonomous components is already included in other values. The value of (I) is not biased by excluding imports. However, by netting all imports against $(A)$ we are introducing some element of induced spending which makes this measure of (A) less accurate than would be ideal, although its quantitative importance is not likely to be large.

\footnotetext{
2Some very minor additional items which are part of GNP
} are included in $A$.
To the extent that rates are unchanged, taxes are dependent upon changes in income, and their effect is thereby reflected in consumption ( $\mathrm{C}$ ). However, changes in tax rates are an important discretionary tool of fiscal policy. Therefore some measure of their effect on consumption (C) should be included in autonomous spending (A). As a practical matter, there is no simple, clear-cut way to separate these two components of taxes. To the extent that important changes in tax structure take place, the measure of (A) is weakened, at least in the time periods during, and just after, the change in the tax structure. There was an important change in the tax structure in 1964 which makes the observed retation between (A) and (Y) or (C) weaker than was really the case. However, no major change in the tax structure is likely for 1967 so the use of (A) in forecasting 1967 will not be seriously impaired.

Another important issue with respect to the incomeexpenditure theory has to do with the fact that (A) is not only the theoretical determinant of (Y) but also an accounting component of (Y). That is:

$\mathrm{Or}$

$$
\text { 4. } \mathrm{Y}=\mathrm{I}+\mathrm{A} \quad \text { [Accounting definition] }
$$

And

$$
\text { 4a. } \Delta Y=\Delta I+\Delta A
$$

$$
\text { 5. } \Delta \mathrm{Y}=\mathrm{a}+\mathrm{b}(\Delta \mathrm{A}) \quad \text { [Theoretical assumption] }
$$

Any statistical test of the theoretical relation between $(\triangle A)$ and $(\Delta Y)$ would give a much closer link between the two variables than would actually be the case, because in an accounting sense $(\triangle A)$ is included in $(\triangle Y)$. This problem has been handled by relating $(\triangle A)$ to $(\triangle Y)$ with a onequarter time lag which breaks the link with the accounting definition. An alternative and perhaps conceptually superior method would be to compare $(\triangle A)$ only with those components of $(\triangle Y)$ which are not included in $(\triangle A)$. Because $(\triangle \mathrm{Y}-\triangle \mathrm{A}=\Delta \mathrm{I})$ this would mean comparing $(\triangle A)$ with $(\Delta \Gamma)$. If

6. $\Delta \mathrm{I}=\mathrm{c}+\mathrm{d}(\Delta \mathrm{Y})$ [Because induced spending (I) depends upon current income (Y).1

Then

$$
\begin{aligned}
& \Delta \mathrm{I}=\mathrm{c}+\mathrm{d}(\Delta \mathrm{I})+\mathrm{d}(\Delta \mathrm{A}) \quad \begin{array}{c}
{[\text { Because }(\mathrm{Y}) \text { can be }} \\
\text { written as }(\mathrm{I}+\mathrm{A}) .]
\end{array} \\
& \Delta \mathrm{I}(\mathrm{I}-\mathrm{d})=\mathrm{c}+\mathrm{d}(\Delta \mathrm{A}) \quad \begin{array}{r}
\text { [Collecting all }(\mathrm{I}) \text { terms } \\
\text { on the left-hand side. }
\end{array} \\
& 7 . \Delta \mathrm{I}=\frac{\mathrm{c}}{\mathrm{l}-\mathrm{d}}+\frac{\mathrm{d}}{\mathrm{I}-\mathrm{d}}(\Delta \mathrm{A}) \begin{array}{l}
\text { [Dividing both sides } \\
\text { by (1-d).] }
\end{array}
\end{aligned}
$$

Thus, $(\triangle \mathrm{I})$ depends upon $(\Delta \mathrm{A})$.

When this relation is tested statistically, the results are as follows:

$$
\text { 7a. } \Delta \mathrm{I}=3.42+\underset{(.133)}{.550(\Delta \mathrm{A})_{\mathrm{t}-1} \quad \mathrm{r}^{2}=.372}
$$

These results are statistically significant and almost as good as equation $2 \mathrm{a}$ in the text which relates (A) to (Y). 
It is interesting to note that when changes in money are compared with changes in induced spending only, the results are actually superior to money related to GNP.

8. $\Delta \mathrm{I}_{\mathrm{t}}=3.61+2.13(\Delta \mathrm{M})_{\mathrm{t}-\mathrm{s}}$ (.35)

$$
\mathrm{r}^{2}=.591
$$

Friedman and Meiselman observed this supenior relation in their study and attributed it to the fact that money should be related to permanent (rather than observed) income and that consumption or induced spending is superior to $(\mathrm{Y})$ as a proxy for permanent income.

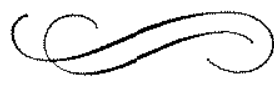

